\title{
A 3-year retrospective review of corneal ulcers in Hospital Universiti Sains Malaysia
}

\author{
JIN YI YAP ${ }^{1,2, A-F}$, KAAI VOON TAN ${ }^{1, B-E}$, SONNY-TEO KHAIRY-SHAMEL 1, A, D, E \\ ORCID ID: 0000-0003-0996-7632 \\ ${ }^{1}$ Department of Ophthalmology, School of Medical Sciences, Universiti Sains Malaysia, Kota Bharu, Kelantan, \\ Malaysia \\ ${ }^{2}$ Department of Surgery, School of Medical Sciences, Universiti Malaysia Sabah, Kota Kinabalu, Sabah, Malaysia
}

A - Study Design, B - Data Collection, C - Statistical Analysis, D - Data Interpretation, E - Manuscript Preparation, F - Literature Search, G - Funds Collection

Summary Background. Microbial keratitis which is also known as corneal ulcer, is a common ocular infection that can result in debilitating monocular visual impairment. Identifying the prevalence and the latest trend of the causative agents will be useful in the management of corneal ulcer.

Objectives. To evaluate the demographic and epidemiology factors of microbial keratitis at a tertiary hospital in a rural state of Malaysia. Material and methods. This is a retrospective review with a total recruit of 137 patients who were admitted to the Ophthalmology ward in Hospital Universiti Sains Malaysia. A retrospective review of the demographic data and results of corneal tissue sampling were documented.

Results. Demographic data showed similarity to other studies where it affected most commonly in the productive age. It was also more commonly seen in male patients than in female. Bacterial keratitis (51.1\%) was found to be more common than fungal keratitis (24.8\%). In cases of bacterial keratitis, Pseudomonas spp. was the commonest causative agent, while in cases of fungal keratitis, Fusarium spp. was the commonest fungus microbial agent.

Conclusions. With the knowledge of the demographical and epidemiological factors of microbial keratitis of a region, clinicians will be able to initiate prompt treatment at the early stages of the disease. Thus, less complications will arise from the disease and a better visual outcome provided.

Key words: keratitis, cornea, Malaysia.

Yap JY, Tan KV, Khairy-Shamel S-T. A 3-year retrospective review of corneal ulcers in Hospital Universiti Sains Malaysia. Fam Med Prim Care Rev 2019; 21(1): 62-65, doi: https://doi.org/10.5114/fmpcr.2019.82980.

\section{Background}

Microbial keratitis which is also known as corneal ulcer, is a common ocular infection that can result in debilitating monocular visual impairment. It is a process of corneal inflammation due to overlying epithelial damage. Corneal ulceration can result in scarring formation when the stromal is affected and can be blinding when there is scar formed the visual axis. Besides scarring, corneal ulcer can also result in endophthalmitis and phthisis bulbi if the infection crosses into the intraocular system. These can thus result in severe visual impairment [1].

Malaysia is a developing country and consists of a multiracial population of approximately 28 millions. Based on the national eye survey, in Malaysia, in 1996, corneal disease affected about $3.42 \%$ of the total population and ranked the fourth commonest cause resulting in low vision or blindness [2]. In Myanmar, another South East Asia country, unilateral blindness caused by corneal ulcer had an incidence of 710 over 100,000 of the population [3]. Similarly, the World Health Organization (WHO) reported $4 \%$ of all blindness are caused by corneal opacities [4].

As mentioned, any ocular injury can result in corneal ulcer formation. Rather than waiting for the formation of corneal ulcer, identifying the risk factors and predicting the possible complications based on the epidemiology study would help to prevent the disease. When there is an early sign of ulcer formation or even only mild ocular injury that can predispose to corneal ulcer, primary care practitioners can play a major role in initiating the treatment [5].
In the primary care setting, early management can be started based on the latest update of the epidemiology. Based on the epidemiology studies, primary care practitioners can initiate anti-microbial treatment as early as the diagnosis is made at the primary care setting [6]. WHO guidelines for management of corneal ulcer in the Southeast Asia region of the year 2004 suggest that patients who come in with superficial ocular injury such ash corneal abrasion should be administered the ointment Chloramphenicol for at least 3 times per day [6]. Moreover, they should be followed-up daily and be referred to secondary or tertiary centers if there are signs of worsening [6].

\section{Objectives}

The incidence of corneal ulcer leading to monocular blindness worldwide, including Malaysia, is significant. Thus, our objective is to identify the prevalence, the causative risk factors and the latest trend of the causative agents of corneal ulcer. This will be useful in achieving early management and referral to tertiary hospitals from the primary care setting.

\section{Material and methods}

\section{Study design}

This was a retrospective, single centre, observational study. 


\section{Setting}

The Institutional involved is Hospital Universiti Sains Malaysia (HUSM), a medical teaching centre for the east coast region of West Malaysia, located in the state of Kelantan. The study involved patients who were admitted to the ophthalmology ward for microbial keratitis treatment from the $1^{\text {st }}$ of January 2015 to $31^{\text {st }}$ December 2017.

\section{Participants}

The study only included the patients diagnosed as having microbial keratitis caused either by bacterial or fungal organisms. Other type of ulcer such as viral ulcers, neurotropic ulcers, Mooren ulcers, marginal ulcers and ulcers associated with autoimmune conditions were excluded.

Detailed history of all the patients recruited in the study were taken to investigate the causative risk factors of the corneal ulcer. Furthermore, they were examined via slit lamp, and clinical findings were recorded. Further investigations were then carried out; corneal scrape was undertaken with a $21 \mathrm{G}$ needle under slit lamp microscope and a smear prepared for Gram stain. Corneal material was also smeared onto blood agar, chocolate agar, Sabouraud dextrose agar and McConkey medium. Microbiology laboratory proceeded with examination and the final report of the microbial examination was produced.

\section{Variables}

As mentioned, corneal ulceration was defined as corneal infiltration with loss of overlying epithelium associated with signs of inflammation. The centre consists of a senior cornea consultant who oversaw and was involved in the management of all the cases included in the study. Only those who were diagnosed with corneal ulcer by the corneal consultant were included in the study.

\section{Data source}

Data was collected via the records of admission in Ophthalmology ward Hospital Universiti Sains Malaysia from the $1^{\text {st }}$ of January 2015 to $31^{\text {st }}$ December 2017. Once patients' identity was identified, patients' records were traced and studied at hospital unit records. Patients' demographic details, history when having corneal ulcer and investigation results were documented accordingly.

\section{Study size}

Study size of this retrospective study was based on all corneal ulcer patients that were admitted to ophthalmology ward of the given period of this study.

\section{Statistical methods}

The statistical method used in this study was descriptive statistics. Patients' demographic data including their age, sex and ethnicity were collected in this study. The mode, median and mean of these data was analysed and described. The same statistical methods were applied to the causative risk factor and causative agents of corneal ulcer of this study.

The research followed the Declaration of Helsinki. It did not require the consent of the Bioethics Commission.

\section{Results}

\section{Participants}

There were a total of 137 patients enrolled into the study. All patients were admitted to Ophthalmology ward in Hospital Universiti Sains Malaysia (HUSM) of Kelantan throughout January 2015 to December 2017.

\section{Descriptive data}

The male to female ratio was 1.85 . The mean age at the diagnosis of corneal ulcer was 48.6. The youngest patient was at the age of 12 , while oldest was at the age of 89 . Individuals of ages from 21 to 60 contributed more than $50 \%$ of the total number of patients. As the population of Kelantan mainly came from the Malay ethnicity, the Malay population contributed $97.1 \%$ of all corneal ulcer patients. Table 1 showed the prevalence of corneal ulcer at our centre from the year 2015 to 2017 by age, sex and ethnicity.

Table 1. Prevalence of corneal ulcer at HUSM by age, sex and ethnicity of year 2015-2017

\begin{tabular}{|l|l|}
\hline & $n(\%)$ \\
\hline$<21$ & $9(6.6)$ \\
\hline $21-40$ & $42(30.7)$ \\
\hline $41-60$ & $35(22.5)$ \\
\hline $61-80$ & $44(32.1)$ \\
\hline$>81$ & $7(5.1)$ \\
\hline Total & $137(100)$ \\
\hline Sex & $89(65)$ \\
\hline Male & $48(35)$ \\
\hline Female & \multicolumn{2}{|l|}{} \\
\hline Ethnicity & $133(97.1)$ \\
\hline Malay & $4(2.9)$ \\
\hline Chinese & $0(0)$ \\
\hline India & \multicolumn{2}{|l|}{} \\
\hline
\end{tabular}

\section{Outcome data}

\section{Causative risk factors for corneal ulcer}

From the detailed history from patients, causative risk factors were identified. Based on the analysis, the main cause of corneal ulcers was due to ocular surface damage. This was further divided based on the types of causative agent into organic and non-organic types. This division revealed that up to $51.1 \%$ ( $n=70$ ) of the corneal ulcers were caused by organic matter, while $19.7 \%$ ( $n=27$ ) of total were caused by non-organic matter. The second commonest risk factor was contact lens related corneal ulcer. Herein, $20.4 \%(n=28)$ of all corneal ulcers were caused by contact lens. What is more, $1.5 \%(n=2)$ of all patients had underlying ocular surface disease which also made them prone to infection. Finally, about $7.3 \%(n=10)$ of all patients did not have any identifiable cause for their corneal ulcers.

\begin{tabular}{|l|l|}
\hline \multicolumn{2}{|l|}{ Table 2. Causative risk factors for corneal ulcers in HUSM } \\
\hline Risk Factors & $n(\%)$ \\
\hline Trauma & \\
\hline Organic & $70(51.1 \%)$ \\
Non organic & $27(19.7 \%)$ \\
\hline Contact lens related & $28(20.4 \%)$ \\
\hline Ocular surface disease & $2(1.5 \%)$ \\
\hline Others & $10(7.3 \%)$ \\
\hline Total & 137 \\
\hline
\end{tabular}

\section{Causative agents of corneal ulcer}

All patients diagnosed as having corneal ulcer based on history and clinical examination were investigated for corneal tissue culture and sensitivity. Only the organisms isolated from the first corneal tissue culture at initial presentation were taken into account. The organisms isolated are summarized in Table 3. 
From Table 3 we can see that most of the infective keratitis were bacterial, with percentages up to $51.1 \%(n=70)$. Herein, up to $33.6 \%(n=46)$ of the total cases were caused by gram negative bacteria. Among the gram negative bacteria, Pseudomonas spp. was the commonest causative agent, reaching up to $27.1 \%(n=37)$ of all cases. For gram positive bacteria, Staphylococcus aureus and Streptococcus pneumonia were the two main causative bacteria. These accounted to $9.5 \%(n=13)$ and $7.3 \%$ ( $n=10)$ of all cases, respectively. There was no mixed infection of bacterial or fungal keratitis found in this study.

\begin{tabular}{|l|l|}
\hline \multicolumn{2}{|l|}{ Table 3. Organism isolated from the infected corneal tissues } \\
\hline Organism isolated & $n(\%)$ \\
\hline Bacteria & $\mathbf{7 0}(\mathbf{5 1 . 1})$ \\
\hline Gram positive bacteria & $\mathbf{2 4}(\mathbf{1 7 . 5 )}$ \\
\hline Staph aureus & $13(9.5)$ \\
\hline Strep pneumoniae & $10(7.3)$ \\
\hline Corynebacterium spp. & $1(0.7)$ \\
\hline Gram negative bacteria & $\mathbf{4 6}(33.6)$ \\
\hline Pseudomonas spp. & $37(27.1)$ \\
\hline Aeromonas spp. & $1(0.7)$ \\
\hline Neisseria spp. & $1(0.7)$ \\
\hline Moraxella spp. & $1(0.7)$ \\
\hline Citrobacter spp. & $1(0.7)$ \\
\hline Enterobacter spp. & $2(1.5)$ \\
\hline Burkholderia spp. & $1(0.7)$ \\
\hline Serratia spp. & $2(1.5)$ \\
\hline Fungus & $\mathbf{3 4}(24.8)$ \\
\hline Candida spp. & $8(5.8)$ \\
\hline Aspergillus spp. & $2(1.5)$ \\
\hline Fusarium spp. & $13(9.5)$ \\
\hline Curvularia spp. & $6(4.4)$ \\
\hline Non sporulating mold & $5(3.6)$ \\
\hline No organism isolated & $33(24.1)$ \\
\hline Mixed infection & $0(0)$ \\
\hline Total & $\mathbf{1 3 7}(\mathbf{1 0 0 )}$ \\
\hline & \\
\hline
\end{tabular}

Cases of fungal corneal ulcer accounted for $24.8 \%(n=34)$ of all cases of corneal ulcer. The commonest fungus causing fungal keratitis in our study was Fusarium spp.. This contributed to 9.5\% ( $n=13$ ) of all cases, followed by Candida spp. with $5.8 \%$ $(n=8)$ reported.

\section{Discussion}

\section{Key results and interpretation}

The study was done in one of the poorest and most underdeveloped states in Malaysia. Demographically, Kelantan state is located in the northeast of peninsula Malaysia bound by Thailand in the north, the South China Sea in the northeast, Terengganu in the east, Pahang in the south and Perak in the west. Based on the reports from Department of statistics Malaysia, the population of Kelantan by the year of 2016 was 1.8 million [7]. Its GDP per capita in year 2016 was RM12, 812, compared to RM101, 420 for the capital of Malaysia, Kuala Lumpur. GDP income for Kelantan were mainly contributed via the agriculture sector, which accounted for $24.6 \%$ of the total income of the state [8]. This figure shows that the socioeconomic status for the Kelantan state is relatively lower compared to the more advanced states in Malaysia. This can be one of the very important factors contributing to the trend of corneal ulcer in Kelantan, as the socioeconomic status does affect the epidemiological and etiological factors of microbial keratitis [4].

Table 1 describes the prevalence of corneal ulcer by different ranges of age. Corneal ulcer occurred most commonly within the productive age group - from 21 years old to 60 years old. As indicated, the age group $21-60$ years contributed $53.2 \%$ $(n=77)$ of all cases of corneal ulcer. Such cases come about due to the inoculation of foreign bodies into the eyes at work [4, 9]. This is also evidenced in Table 2. This happenstance is correlated to the socio-economy status of individuals in Kelantan state, as the main income depends upon the agricultural sector. The agricultural sectors within which the patients in Kelantan state find employment include palm oil plantation work, paddy field work, fruit farming and vocational gardening. However, the younger group of patients have different risk factors wherein the most common cause of corneal ulcer is due to contact lens wear. The trend of contact lens related corneal ulcer is increasing due to the higher usage of contact lens among the younger generation [4].

A similar study done at HUSM back in year 2008 was conducted for a period of 16 months. The study, however, had a smaller sample size and only 29 patients were observed. By comparison to this study, bacterial keratitis was still mainly caused by gram negative bacteria. Moreover, Pseudomonas spp. was also the main causative agent for bacterial keratitis and accounted for $58.6 \%$ of all cases at that time [10]. However, in our study, Pseudomonas bacterial keratitis was relatively reduced to $27.1 \%$. For the gram positive bacteria, the previous statistic showed higher incidence of Streptococcus keratitis infection. The current statistic shows the presence of both Staphylococcus and Streptococcus keratitis infection at the same levels. This could be due to the larger sample size.

As for fungal ulcer, a 5 years retrospective study was carried out in HUSM specifically on fungal keratitis. This included a total of 41 patients. The main fungus inducing fungal keratitis therein was also Fusarium spp. This accounted for $46 \%$ of all fungal keratitis cases [11]. In our study, we found the comparable figure to be $38.2 \%$ of all fungal keratitis cases. What is more, the number of fungal keratitis caused by Candida spp. were relative higher in our study as it accounted for $23.5 \%$ of all the fungal keratitis (versus $12.2 \%$ of all cases in the previous study). Other species such as Curvularia spp. and non-sporulating mold were also seen to be present in the previous study.

\section{Limitations of the study}

Hospital Universiti Sains Malaysia was still using a manual filing system for patients' records. Therefore, we faced difficulties in tracing the case histories of the study population. Moreover, records are only kept for three years. This limits the sample size. The study was also done without any financial aid from any grant from any organizations or personnel. Therefore, we were unable to hire research assistants for data collection.

\section{Conclusions}

In conclusion, it is important to understand and update our knowledge regarding the prevalence and the risk factors of regional corneal ulcer. Doing so can assist in the initial prompt treatment for the patient before waiting for laboratory results. Early prompt treatment can help to reduce the severity of the disease and improve the visual outcome of the patients. In addition, primary care clinicians should be involved in providing early management and treatment to the patients, as patients come to them prior to tertiary referral. 
Source of funding: This work was funded from the authors' own resources.

Conflicts of interest: The authors declare no conflicts of interest.

\section{References}

1. Farrar J, Hotez P, Junghans T, et al. Manson tropical infectious diseases. 23rd ed. Elsevier; 2014.

2. Zainal M, Ismail SM, Ropilah AR, et al. Prevalence of blindness and low vision in Malaysia population: results from National Eye Survey 1996. Br J Ophthalmol 2002; 86(9): 951-956.

3. Maung N, Thant CC, Srinivasan M, et al. Corneal ulceration in South East Asia. II: a strategy for the prevention of fungal keratitis at the village level in Burma. Br J Ophthalmo 2006; 30: 968-970, doi: 10.1136/bjo.2006.094706.

4. Ratnalingam V, Umapathy T, Sumugam K, et al. Microbial keratitis in West and East Malaysia. Int Eye Sci 2017; 17(11): 1989-1992.

5. Cronau H, Kankanala RR, Mauger T, et al. Diagnosis and management of red eye in primary care. Am Fam Physician 2010; 81(2): 137-144.

6. Upadhyay MP, Srinivasan M, Witcher JP. Diagnosing and managing mircrobial keratitis. Comm Eye Health J 2015; 28 (89): 3-6.

7. Department of Statistic Malaysia. Gross Domestic Product by State 2016 [cited 18.04.2018]. Available from URL: https://www.dosm. gov.my/v1/index.php?r = column/pdfPrev\&id = VS9Gckp1UUpKQUFWS1JHUnJZS2xzdz09.

8. Department of Statistic Malaysia. Statistic on Kelantan state [cited 18.04.2018]. Available from URL: https://www.dosm.gov.my/v1/ index.php?r = column/cone\&menu_id = RU84WGQxYkVPeVpodUZtTkpPdnBmZz09.

9. Srinivasan M, Upadhyay MP, Priyadarsini B, et al. Corneal ulceration in south-east Asia III: prevention of fungal keratitis at the village level in south India using topical antibiotics. Br J Ophthalmo 2006; 90: 1472-1475.

10. Norina TJ, Raihan S, Bakiah S, et al. Microbial keratitis: aetiological diagnosis and clinical features in patients admitted to Hospital Universiti Sains Malaysia. Singapore Med J 2008; 49(1): 67-71.

11. Fadzillah MT, Norhayati A, Ishak SR, et al. A 5-year retrospective review of fungal keratitis at Hospital Universiti Sains Malaysia. Interdiscip Perspect Infect Dis 2012; 2012: 1-6, doi: 10.1155/2012/851563.

Tables: 3

Figures: 0

References: 11

Received: 3.06.2018

Reviewed: 10.06.2018

Accepted: 26.08 .2018

Address for correspondence:

Jin Yi Yap, MD

Department of Ophthalmology

School of Medical Sciences

Universiti Sains Malaysia

16150 Kota Bharu

Kelantan

Malaysia

E-mail: yjy16my@gmail.com 